\title{
Functions of Piano Accompaniment in Basic Training and Teaching of Dance and Ability Training
}

\author{
Chao Qu \\ Taishan University, Tai'an, 271000, China
}

\begin{abstract}
Keywords: Piano accompaniment; Basic training and teaching of dance; Cultivation of accompaniment ability
\end{abstract}

\begin{abstract}
The dance is a kind of visual art displayed in certain space, and the music is a kind of auditory art displayed in certain space and time; from ancient time to the present, the dance and music are inseparable, and only their combination can realize the highest state of the art. Therefore, in the basic teaching of dance, the piano is an essential part and it can be used to shape certain auditory artistic conception and then sublimate the dance art. The piano accompaniment plays a facilitation role in the basic training and teaching of dance and it can help to improve the level and efficiency of basic training and teaching of dance.
\end{abstract}

\section{Introduction}

From ancient time to the present, the dance art and music art always supplement each other, and their independent existence is monotonous and can't stimulate people's deep feeling of art. Through beautiful music accompaniment, it is able to stimulate the dancers' deep understanding of art, bring strong visual impact on audience, and then lead people to step into the peak of art. Therefore, the piano accompaniment is very important for basic training and teaching of dance, and the piano accompaniment of dance is just to promote dancers' understanding of dance music in the dance teaching process. Different from common piano music, the piano accompaniment mainly serves for dance; it is played according to dancers' condition and body and used to help dancers to complete the understanding and mastering of all dancing movements. The function of common piano accompaniment is to help students to master the rhythm of dance music and take dance with sense of beauty. The dance piano accompaniment teachers can help students to know more styles of dance music and know the subtle difference in movements through piano accompaniment so as to promote students to realize the change from passive understanding to active release of feeling.

\section{Functions of piano accompaniment in basic training and teaching process of dance}

\section{To help students to find the sense of rhythm and sense of music so as to get a deeper understanding of dance movement}

In the process of dance teaching, if the dance teachers only make beats, the students can only rigidly memorize the dance movements and get no understanding of the charm of whole dance music, thus the dance neither has vitality nor has sense of beauty. Therefore, we need to make use of piano accompaniment to assist the dance teaching. Through use of music, it is able to firstly create a kind of corresponding auditory effect for students and then bring dancers into an atmosphere same with the artistic conception of dance music. In case of long-term application of piano accompaniment, it is able to improve the dance learners' aesthetic ability to music and find the rhythm of music; in the whole process of dance teaching, the students can understand dance movements through piano accompaniment. Therefore, the piano accompaniment is very important for dance learners, especially learners without any dance foundation. As for students without foundation, the accompaniment teachers shall make use of active guidance and adjustment to positively guide students to complete the dance movements together with rhythm. 


\section{To render the environment and help learners to understand the artistic conception of movements}

In the basic training and teaching process of dance, the piano accompaniment has strong infection and renders certain music environment, thus it can quickly help the students to understand the style and feeling of dance, enter the atmosphere consistent with the artistic atmosphere required in dance, and then show the dance movements through their own feelings. The music mainly shows the fluctuation in feelings through harmony, rhythm, and melody, and the dance mainly shows the different feelings via limbs, eye expression, and facial expression. The dance brings great visual impact on people; however, without music rendering, it is very difficult to bring the audience to the artistic conception. Therefore, the piano accompaniment can motivate learners' body expression and finally realize perfect combination of music and dance. Certainly, it is required to make use of emotional accompaniment to cultivate students' music appreciation ability in the process of long-term basic training and teaching of dance. The piano accompaniment is not just a setoff to the basic training of dance, but to help the dancers to show richer feelings via body expression and then promote dancers to realize final understanding of dance.

\section{To enhance the sense of rhythm of dance}

A complete dance movement is coherent and changing, thus it is very hard for the beginners to master the change and details. Through piano accompaniment, it is able to enhance the sense of rhythm of dance for convenience that the students can understand the rhythm and corresponding movements contained in the dance. In the traditional basic training and teaching of dance, the dancer teachers let students master the movements through making beats. However, it is greatly difficult for dance learners to learn dance via beats and then show the dance according to music. In the dance teaching, through direct use of piano accompaniment, the students can show the dance movements according to different tone and melody. Only beautiful music can truly stimulate students' internal emotion and understanding of dance, and only affective dance can be especially moving.

\section{To motivate dancers' creation inspiration}

In the basic training and teaching of dance without piano accompaniment, the students can only memorize dance steps and perfect body movements through the beats made by dance teachers, the whole process is under the state of passive memory, and the students can't truly understand the dance art. However, through basic training and teaching of dance with piano accompaniment for a long time, it is able to help students to improve the ability of artistic appreciation and get their own understanding of dance art so as to obtain the creation inspiration on dance and dance out their own dance style. In the basic training and teaching of dance, some students with high talent can get quick understanding in the music. As for students with poor music talent, they can also get the assistance from piano accompaniment and enter into certain dance realm, thus the piano accompaniment can play a strong promotion function.

\section{To motivate students' dance interest}

The dance is an elegant expression of body art, and it is an effective means to cultivate students' elegant sentiment. Therefore, in order to learn dance art, the students shall get basic mastery of dance and get their own understanding of dance art. However, due to different dance talent, there will be different result in their understanding of dance.

There are various kinds of piano accompaniment; in the basic training and teaching of dance, the piano accompaniment can bring colorful visual experience to students. A good piano accompaniment teacher can play different accompanied music according to students' personality and talent so as to infect students, stimulate students' learning interest in dance, and create a good learning atmosphere of dance as much as possible. As long as their learning interest in dance is improved, they can actively learn and research the dance and then realize the learning purpose of dance. 


\section{To improve students' artistic culture in dance and music}

Through visual and auditory impact on people, the dance and music art can help people to form their internal feeling, which is the enjoyment brought through perfect combination of two kinds of arts. In the long-term basic training and teaching of dance, through utilization of piano accompaniment to assist the teaching, it is not only able to help students to learn dance, but also able to improve students' music accomplishment. The beautiful piano accompaniment can also help to further improve students' ability of dance appreciation. According to different form of expression of accompaniment, we can know the affective change of dance, and then transform the music into body movements through our own understanding, thus the emotion consistent with artistic conception can be shown to realize the most perfect state of the dance.

\section{Piano accompaniment teachers' ability training}

There are many kinds of dance, and the dance piano accompaniment requires the teachers to get a deep understanding of dance and music, thus it is able to realize a skillful combination of dance and music and express dance steps and rhythm in an appropriate way. Therefore, people think that the piano accompaniment is a kind of art with high difficulty. Then, as a qualified piano accompaniment teacher, he or she shall cultivate students' learning ability from following aspects.

\section{To know and master relevant knowledge of dance}

As a qualified piano accompaniment teacher, he or she shall skillfully know relevant knowledge of dance, and know the development and rule of dance. While the development course of dance is fully mastered, they can understand how to identify the difference between dance, and then provide the best accompaniment music and formulate high-quality basic training course of dance. The piano accompaniment teachers shall clearly know the dance features, rules of dance music, and body language of dance; in this way, in the playing process, they can provide corresponding music accompaniment according to students' dance level.

\section{To know the training purpose of basic training course of dance and provide the most suitable music accompaniment}

Before the accompaniment in the basic training and teaching of dance, the dance piano accompaniment teachers shall know that each dance movement shall have certain significance and different training requirement. Therefore, the dance piano accompaniment teachers and dance teachers shall make detailed communication and discussion to select the most appropriate accompanied music style so as to help the students to understand the dance.

Besides, the dance piano accompaniment teachers shall pay attention to the diversity of music. In the process of basic training and teaching of dance, while the teachers face different dance objects with different physical condition and dance foundation, they shall provide different music accompaniment and different playing method. In this way, it is able to help students to get a deeper understanding of dance.

\section{To get large quantity of resource reserve of dance accompaniment music and extemporaneous accompaniment ability}

The basic training and teaching of dance has wide content and different style, thus the dance piano accompaniment teachers shall provide different accompaniment music for each course, and even provide matching accompaniment music for each movement, thus the dance piano accompaniment teachers shall reserve large quantity of accompanied music. Due to the fact that China's professional dance teaching starts lately, there is small music reserve of dance teaching. In the process of basic training and teaching of dance, the repeated use of same accompanied music can easily let the learners produce auditory fatigue and then lose their enthusiasm in music appreciation, which greatly reduces the quality of basic training and teaching of dance. Through school practice, it proves that it is able to help students to improve their ability in music appreciation, the ability in understanding the 
music, self-creation ability, and dance expression through attempts in music accompaniment of different style and different music. Therefore, the dance piano accompaniment teachers shall enhance their reserve as much as possible, and play corresponding accompanied music according to specific dance movement in the teaching process. After collection of many kinds of music accompaniment, the teachers shall also improve their own ability, get their own understanding of music, and then create certain accompanied music.

Due to various contents and complicated dance movements in basic training course of dance, the dance teachers will carry out intensive training according to students' training situation; under this condition, the piano accompaniment teachers shall have the ability of extemporaneous playing. In the basic training and teaching of dance, the situation that the teachers and students meet a strange music may happen, and then the dance piano accompaniment teachers shall have certain cognition ability in rhythm and melody of music so that they can timely be familiar with and play the music. In the playing process, it is also required to observe dancers' body movements to adjust the playing speed of music. Therefore, a qualified dance piano accompaniment teacher shall have the ability in understanding the music and extemporaneous playing.

\section{To realize effective combination of accompaniment music and dance movement}

The dance piano accompaniment teachers shall be clear about their work content and purpose and always serve for dance movement, thus they shall master key points of dance movement and realize perfect combination of music and dance. The dance piano accompaniment teacher shall clearly know the difference in solo and accompaniment. The solo refers to the situation that people play music according to their understanding of music and their emotional change. The accompaniment refers to the situation that the music shall change according to the change of dancers' body to ensure that the dancers can realize the highest realm of art. In the whole basic training of dance, the piano accompaniment is an essential part to students. In the overall dance training, the movements are always disorderly, and there is poor tacit understanding among students; however, through long-term edification under piano accompaniment, it is able to enhance students' understanding of music rhythm and integrate with the music and dance.

\section{To get a deep understanding of artistic connotation and cultural spirit of dance}

As the dance piano accompaniment teachers, their main role is to help students to know music art and dance art, and realize the emotion and culture. Therefore, the dance piano accompaniment teachers shall firstly know the artistic connotation and cultural spirit so as to exert the charm of dance. Each basic training course of dance may require more style of piano accompanied music, thus the piano accompaniment teachers shall communicate with dance teachers in advance, make artistic appreciation on dance in advance, and then realize the most perfect expression of music art. In addition, the dance piano accompaniment teachers shall also appreciate dance art and music art at ordinary times to improve their own artistic level.

\section{To pay attention to expression form of music in dance}

While there is change in environment and emotion, the same music may have different forms of expression. Generally speaking, in the process of basic training of dance, the piano accompaniment teachers shall adjust the form of expression according to overall environment of dance and students' body movement. As for beginners, it is required to slow down the rhythm and provide students with a chance of buffering their memory; at this time, the main functions of dance piano accompaniment teachers are to guide, assist the memory, and assist students to recall the movements. As for students proficient in dance, the teachers can adopt fluent and quick form of expression to make their dance movements more flexible.

In conclusion, the piano accompaniment plays a very important role in the process of basic training and teaching of dance, and it can render classroom atmosphere, and cultivate students' musical sensibility. Through cooperation with piano accompaniment, the students can quickly find the rhythm and be familiar with dance movements. Furthermore, the beautiful piano accompaniment 
can stimulate students' interest and creation inspiration on dance. Therefore, the piano accompaniment plays an assisting role in the basic training and teaching of dance, which proposes a high requirement for piano accompaniment teachers' ability. Therefore, in the basic training course of dance, the dance piano accompaniment teachers shall provide diversified music accompaniment according to students' difference and difference in dance style. In case of emergency, they shall have the ability of extemporaneous playing to provide students with maximum visual impact and help students to rapidly enter into dance atmosphere as much as possible.

\section{Reference}

[1] Hu Yufang. Discussion on Functions of Piano Accompaniment in Dance Teaching and Professional Quality , Marketing Management Garden, 2012 (12).

[2] Sun Si. Discussion on Functions of Piano Accompaniment in Basic Training of Dance , Music Space and Time (theory version), 2012 (09).

[3] Cao Xiaoyun. Dance and Music - Several Thoughts on Piano Accompaniment and Dance Teaching, Public Art, 2012 (16).

[4] Yan Danni. Beautiful Body Originates from Beautiful Musical Note - Functions of Piano Accompaniment in Basic Training and Teaching of Dance , Journal of Beijing Dance Academy, 2009 (04).

[5] Xu Qinping. Discussion on Piano Accompaniment in Basic Dance Training , Art Education, 2009 (04). 